\title{
Article
}

Mycosphere

\section{A novel species of Russula (Russulaceae) from Indian Himalaya}

\author{
Ghosh $\mathrm{A}^{1}$, Das $\mathrm{K}^{2 *}$, Adhikari $\mathrm{S}^{3}$ and Bhatt $\mathbf{R P}^{1}$ \\ ${ }^{1}$ Department of Botany \& Microbiology, H.N.B. Garhwal University, Srinagar, Garhwal-246174, Uttarakhand, India \\ ${ }^{2}$ Botanical Survey of India, Cryptogamic Unit, P.O. Botanic Garden, Howrah - 711103, India \\ ${ }^{3}$ Department of Botany, University of Kalyani, Kalyani, West Bengal - 741235, India
}

Ghosh A, Das K, Adhikari S, Bhatt RP 2016 - A novel species of Russula (Russulaceae) from Indian Himalaya. Mycosphere 7(6), 771-785, Doi 10.5943/mycosphere/7/6/8

\begin{abstract}
Russula indoarmeniaca (R. subg. Russula sect. Paraincrustatae subsect. Lepidinae), which was collected from broadleaf forest of the state of Uttarakhand is presented in this communication as an undescribed species. It is characterized by apricot to orange colored pileus; rugose pileus surface; lamellae with different lengths of forkation; at least 3 lengths of lamellulae; branched, septate, hairlike cuticular hyphae (some hyphae encrusted) with blunt apex sand different types of cystidial apex. Morphological description coupled with the illustrations and phylogenetic placement is given for this new species.
\end{abstract}

Key words - India - macrofungi - new taxon - nrITS - Russulales - taxonomy

\section{Introduction}

The genus Russula Pers. (Russulaceae) is one of the dominant ectomycorrhizal genera and has worldwide in distribution (Singer 1986, Buyck \& Horak 1999, Buyck et al. 2008, Miller et al. 2012, Li et al. 2015). Presently, it has nine subgenera namely, $R$. subg. Compactae, $R$. subg. Heterophyllidia, $R$. subg. Ingratula, $R$. subg. Amoenula, $R$. subg. Incrustatula, $R$. subg. Russula, $R$. subg. Archaea, $R$. subg. Brevipes and R. subg. Malodora. (Sarnari 1998, Hongsanan et al. 2015) This genus shows enormous diversity in India where $c a 135$ taxa (Manjula 1983, Rawla 2001, Atri et al. 1994, Das \& Sharma 2005, Das et al. 2006, 2010, 2013, 2014, Pradeep \& Vrindra 2010, Manimohan \& Latha 2011, Dutta et al. 2015, Paloi et al. 2015, 2016, Hyde et al. 2016) are known so far.

During the course of a macrofungal foray to different parts of Uttarakhand (one of the representative state of western Himalaya in India) one of us (AG) collected a number of wild mushrooms from a broadleaf forest. Detailed macro- and micromorphological examination of these collections revealed an undescribed taxon of the genus Russula. This novel taxon is proposed herein as Russula indoarmeniaca with ITS-based phylogeny and a detailed morphological description coupled with the illustrations.

\section{Materials \& Methods}

\section{Morphological study}

Macromorphological or field characters were duly recorded in the forest or basecamp from the fresh and dissected young to mature basidiomata. Images of these basidiomata were captured 
with the help of Canon PowerShot SX50 HS. Color codes and terms mostly follow Methuen Handbook of Color (Kornerup \& Wanscher, 1978). Samples were dried with a field drier. Micromorphological characters were observed with the help of a compound microscope (Olympus $\mathrm{CH} 20 \mathrm{i}$ ) from dried materials mounted in a mixture of $5 \% \mathrm{KOH}, 1 \%$ Phloxin and $1 \%$ Congo red. Drawings of micromorphological features were made with the camera lucida at $2000 \times$ magnifications. Microscopic photography has done with the respective dedicated cameras attached to the compound microscopes: Olympus CX21iLED and Canon EOS 1200D. Spore-measurements exclude the height of ornamentations and are noted based on the observations of thirty randomly chosen basidiospores. Spore-size measurements and length/width ratios (Q) are presented as: minimum-mean-maximum. Scanning Electron Microscope (SEM) images of basidiospores were obtained from dry spores that were directly mounted on a double-sided adhesive tape pasted on a metallic specimen-stub and then scanned with silver coating at different magnifications in high vacuum mode $(20 \mathrm{KV})$ to observe patterns of spore-ornamentation. SEM work was carried out with a ZEISS EVO 18 SPECIAL EDITION model imported from Germany and installed at USIC Deptt., HNBGU Srinagar (Garhwal) India. Herbarium names are after Holmgren et al. (1990).

\section{DNA extraction, polymerase chain reaction $(P C R)$ and sequencing}

Genomic DNA was extracted from $100 \mathrm{mg}$ of dried basidiome with the InstaGeneTM Matrix Genomic DNA isolation kit (Biorad, USA) following the manufacturer's instructions. The ITS gene region was amplified with primer pairs ITS1F and ITS4B (White et al. 1990). PCR amplification was performed on a thermal cycler (Eppendorf, Germany) programmed for 2 min at $94^{\circ} \mathrm{C}$, followed by 35 cycles of $45 \mathrm{sec}$ at $94^{\circ} \mathrm{C}, 1 \mathrm{~min}$ at $55^{\circ} \mathrm{C}, 1 \mathrm{~min}$ at $72^{\circ} \mathrm{C}$ and a final stage of 10 min at $72^{\circ} \mathrm{C}$. The PCR products were purified using the QIAquick PCR Purification Kit (QIAGEN, Germany).

Both strands of the PCR fragment were sequenced on the 3730xl DNA Analyzer (Applied Biosystems, USA) using the amplifying primers. The DNA sequence of the reverse strand was edited with Sequence Navigator version 1.0.1 (Applied Biosystems). The final consensus sequence was deposited at GenBank to procure the accession number (KX943614).

\section{Phylogenetic analysis}

Phylogenetic analysis based on ITS sequence data was carried out to establish the phylogenetic placement of our isolated taxon. Reference sequences and outgroup were selected from the relevant literature and GenBank. All sequences were aligned with MAFFT v. 7 (Katoh et al. 2002). No manual editing was done within the alignment. Phylogenetic analysis was conducted with Maximum Likelihood (ML) method implemented in MEGA 6.0 (Tamura et al. 2013). Onethousand bootstrap replicates were analysed to obtain nodal support values. The European materials of Russula delica Fr. (from $R$. subg. Brevipes), R. amoenicolor Romagn. and R. violeipes Quél. (both from $R$. subg. Amoenula) were chosen as out group taxa.

\section{Phylogeny}

The multiple ITS sequences of 28 different species of Russula (considering the sequences for all the relevant species of Russula subg. Russula available in GenBank and also those which are appeared in BLAST search) including our isolate (AG 15-695) were analyzed. Our isolated sequence from AG 15-695 (Russula indoarmeniaca) was recovered as a distinct taxon (marked with bold and blue font) on a comparatively long branch in a strongly supported (99\% bootstrap) clade and clustered with GenBank sequences of other two available (in NCBI) species of Russula (belonging to $R$. subsect. Lepidinae) . The phylogenetic tree is presented in Fig. 1.

\section{Taxonomic descriptions}

Russula indoarmeniaca A. Ghosh, K. Das \& R.P. Bhatt sp. nov. Figs. 2,3 MycoBank: MB 818643 


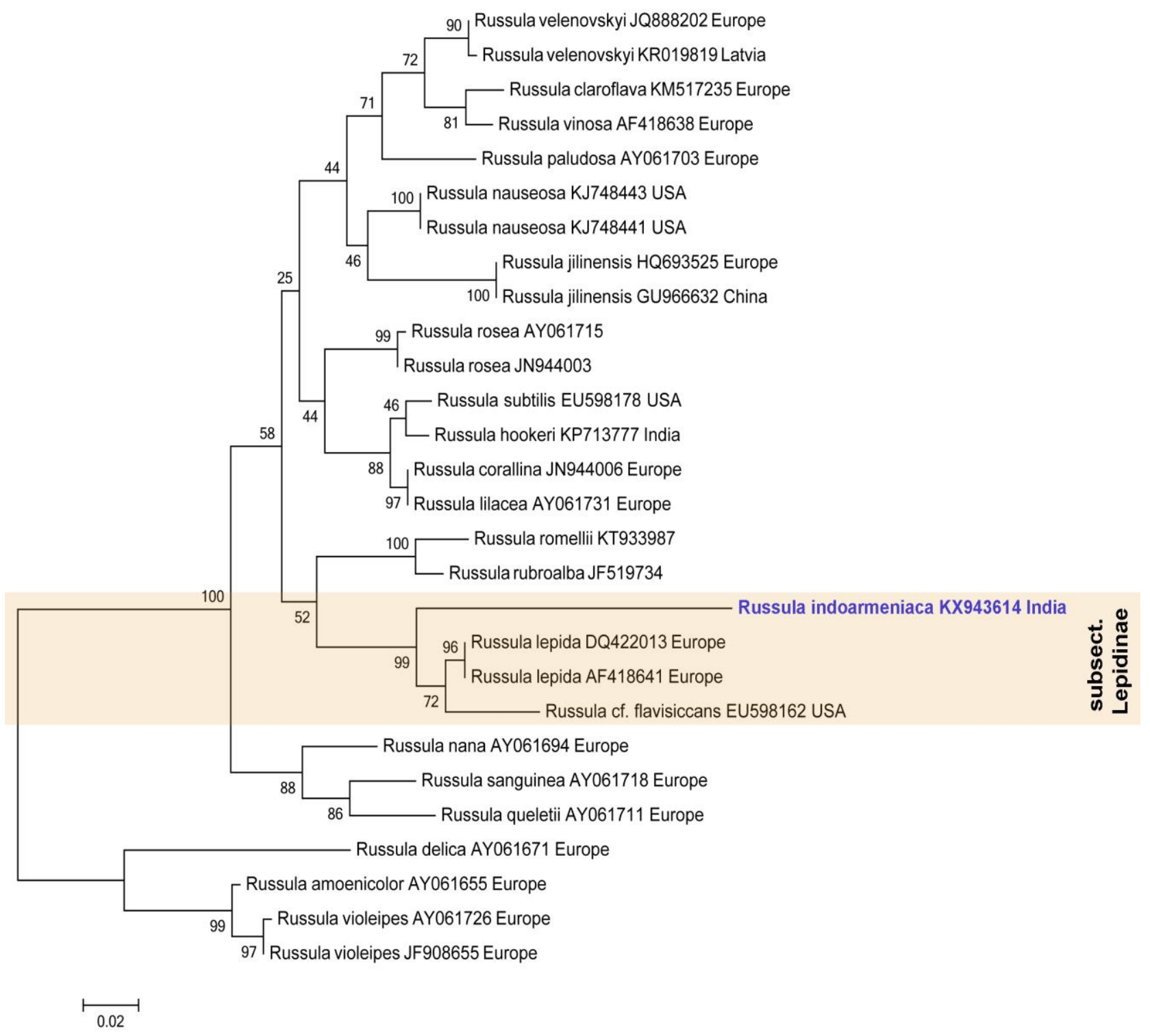

Fig. 1 - Phylogeny of AG 15-695 (Russula indoarmeniaca, in bold, blue font) inferred from Maximum Likelihood analysis of ITS sequences using MEGA 6.0.

Type - India, Uttarakhand: Rudraprayag district, Baniyakund, alt. $2551 \mathrm{~m}, \mathrm{~N} 30^{\circ} 29.213^{\prime}$ E79¹0.246', 18 July 2015, A. Ghosh, AG 15-695 (holotype: CAL; isotype: GUH)

Diagnosis: distinct from other known species of Russula subsect. Lepidinae by a combination of characters: apricot to orange colored coarsely wrinkled cap, yellowish white lamellae with different lengths of forkation, subglobose to broadly ellipsoid basidiospores with long and short spines (up to $1.2 \mu \mathrm{m}$ high) forming partial to incomplete reticulum and cuticular hyphae with blunt tips as described below.

Etymology - referring Indian specimen with 'apricot' colored pileus.

Basidiomata $68-75 \mathrm{~mm}$. in height. Pileus $70-84 \mathrm{~mm}$. in diam., initially convex then planoconvex to applanate with a broad but shallow depression at center on maturity; margin decurved to plane, entire, somewhat striate to sulcate; surface dry, viscid when moist, glossy, coarsely wrinkled (rugose), rimose when mature, apricot-colored, yellowish orange (4A7) or orange yellow (4A7-8, 4B7-8) to orange (5A6-5A7), reddish orange (7A6-7A8) to yellowish white (2A2) spots found over the center and around depression, turning bright yellow (2A7-2A8) with $\mathrm{KOH}$ and reddish brown (8D6-8D8) with guaiacol; pileus context chalky white (1A1-2A1), 
hard, compact, up to $9 \mathrm{~mm}$ thick, thining towards the margin, unchanging when bruished but turning reddish brown (8D6-8D8) with guaiacol. Lamellae adnexed to free, close to rather crowded $(9-11 / \mathrm{cm})$, up to $5 \mathrm{~mm}$ broad, forked near the stipe apex, middle of the cap and near the cap margin also, yellowish white (2A2), entire, with concolorous edges, unchanging when bruised but turning orange (6A6-6A7) to reddish brown (8D6-8D8) with guaiacol; lamellulae present at least 3 lengths. Stipe 50-55 × 14-20 mm, cylindrical to subclavate, tapered towards the base, dry, smooth, brittle, central, chalky white (1A1-2A1); stipe context hard, solid, compact, chalky white (1A12A1), unchanging when bruised but turning reddish brown (8D6-8D8) with guaiacol. Taste somewhat bitterish. Spore print pale cream.

Basidiospores 7-7.43-8 $\times$ 6-6.46-7.4 $\mu \mathrm{m}(\mathrm{n}=30, \mathrm{Q}=1-1.15-1.33)$, subglobose to broadly ellipsoid, rarely ellipsoid, ornamentation amyloid, composed of long and short spines (up to $1.2 \mu \mathrm{m}$ high), mostly aligned or connected to form partial to incomplete reticulum, apiculi up to $2 \mu \mathrm{m}$ high. Basidia 37-60 × 11-16 $\mu \mathrm{m}$, cylindrical, subclavate to clavate, 4-spored, sterigmata up to $10 \mu \mathrm{m}$ high. Subhymenium layer up to $20 \mu \mathrm{m}$ thick, pseudoparenchymatous. Pleurocystidia $60-112 \times 10$ $13 \mu \mathrm{m}$, cylindrical, fusiform to lanceolate with mucronate, appendiculate, rounded, pointed apex or ventricose rostrate, emergent up to $60 \mu \mathrm{m}$, content dense. Gill edges fertile, with basidia and cystidia. Cheilocystidia 37-94 × 7-12 $\mu \mathrm{m}$, cylindrical, subclavate to fusiform with rounded apex. Pileipellis up to $100 \mu \mathrm{m}$ thick, a trichoderm, composed of branched, septate, suberect to erect hair like hyphae (2-5 $\mu \mathrm{m}$ wide) with blunt apex, some encrusted; pileocystidia 4-6 $\mu \mathrm{m}$ broad, cylindrical with rounded or acute apex. Stipitipellis a trichoderm, composed of branched, septate hyphae $(2-4 \mu \mathrm{m}$ wide); some hyphae encrusted. Caulocystidia up to $6 \mu \mathrm{m}$ broad with mostly rounded apex.

Material examined - India, Uttarakhand: Rudraprayag district, Baniyakund, on ground, under Quercus sp mixed broadleaf forest, alt. 2551 m, N 30²9.213' E 79¹0.246', 18 July 2015, A. Ghosh, AG 15-695.

Notes - The combination of macro- and micromorphological features such as pale cream spore print, hard context, somewhat bitterish taste, no blackening hymenial cystidia with sulphovanillin place Russula indoarmeniaca in subg. Russula subsect. Lepidinae (Sarnari 1998). In the field, the present taxon is distinct from other known species of subsect. Lepidinae by its apricot to orange colored cap with reddish orange to yellowish white spots found over the center and around depression, rugose pileus surface that turns bright yellow with $\mathrm{KOH}$ and reddish brown with guaiacol, yellowish white lamellae with different lengths of forkation and presence of at least 3 lengths of lamellulae. Similarly, micro morphologically, presence of subglobose to broadly ellipsoid spores with long and short spines (up to $1.2 \mu \mathrm{m}$ high) forming partial to incomplete reticulum, branched, septate, hairlike partially encrusted cuticular hyphae with blunt apex are also quite distinct. In this subsection, another species $R$. lepida Fr. (appeared to be closest in ITS phylogeny) differs from proposed new species by its dry, matt-pruinose, scarlet, rose-red to whitish pink colored cap, pale cream colored crowded gills, slightly larger spores $(8-9 \times 7-8 \mu \mathrm{m})$ with distinctively smaller warts $(0.1-0.5 \mu \mathrm{m})$ (Sarnari 2005). Russula cf. flavisiccans another taxon belonging to subsect. Lepidinae, also appeared close to the present species in ITS phylogeny but the former differs from newly proposed species in having minutely velvety to pruinose, red to dark red, venetian pink colored cap, adnate to notched lamellae, globose basidiospores with a nearly complete reticulum, strongly acicular to ciliate epicuticular hyphae (Bills 1989). Russula amarissima Romagn. \& E.-J.Gilbert also from subsection Lepidinae, differs from $R$. indoaurantiaca by its violaceous purple to cigar brown, exceptionally bright and relatively pure red colored pileus, context that strongly changes to saffron, lager spores $(7.6-9-9.5 \times 6.4-8-8.4 \mu \mathrm{m})$ with thin smaller warts [more or less pointed $(0.6 \mu \mathrm{m})$, sometimes up to $0.8-1 \mu \mathrm{m}$ ], forming an incomplete reticulum (Sarnari 2005).

In the field, Russula indoarmeniaca resembles with Russula aurea Pers., R. aurora Krombh., R. aurantiaca (Jul.Schaff.) Romagn., R. lepidicolor Romagn. Russula aurea differs from present taxon by possessing crowded ochraceous lamellae with bright golden yellow edges, yellow flushed stem, mild taste, pileipellis without dermatocystidia, lager spores $(7-10 \times 8.5-9 \mu \mathrm{m})$ with 


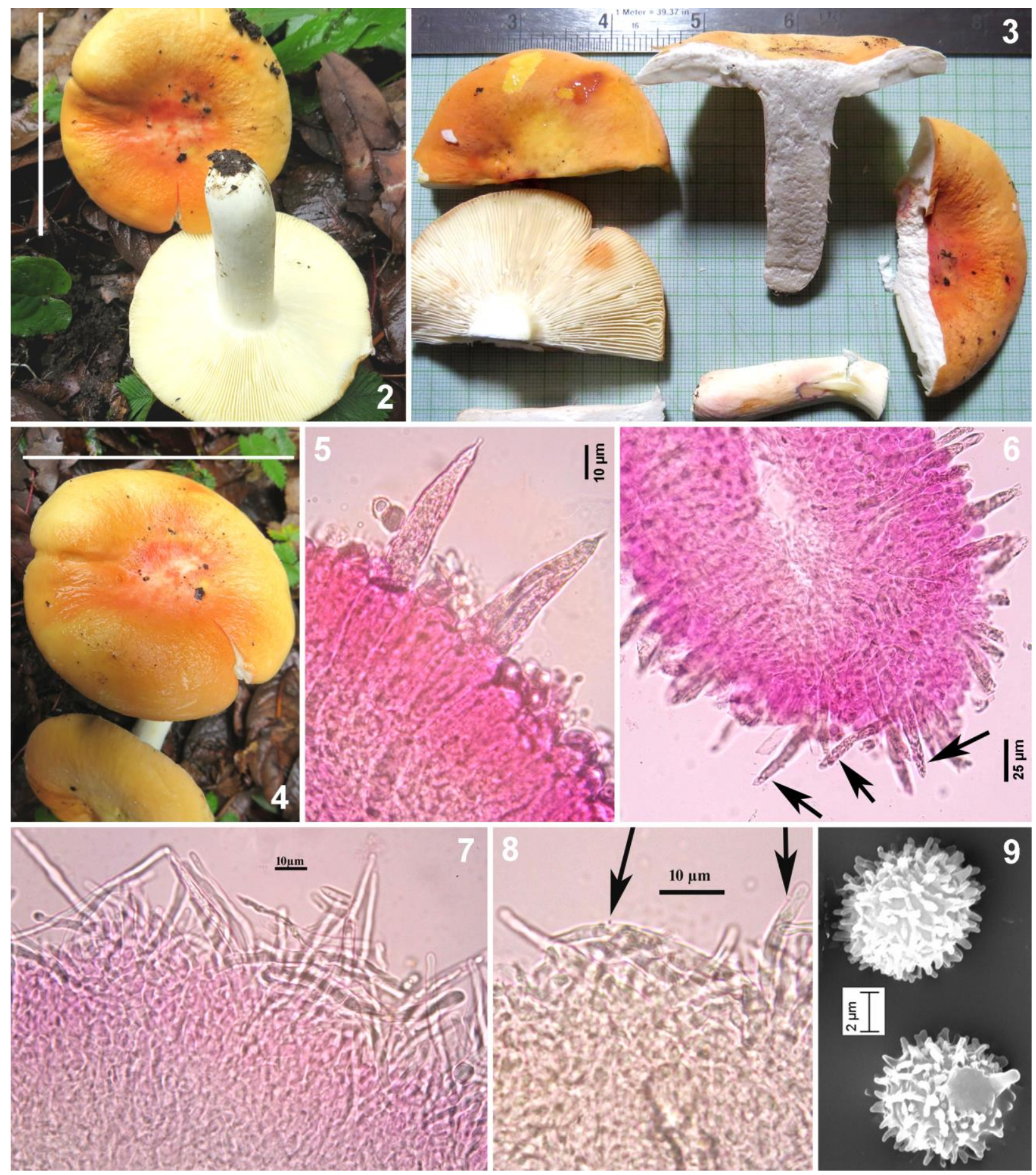

Figs. 2-9 - Russula indoarmeniaca (from holotype, AG 15-695). 2-4. Fresh basidiomata in the field and base camp. 5. Transverse section through lamellae showing pleurocystidia. 6. Transverse section through lamellae showing Cheilocystidia. 7. Radial section through pileipellis showing elements of pileipellis. 8. Pilear hyphae with encrustrations. 9. SEM images of basidiospores. Bars $2,4=100 \mathrm{~mm} .5=10 \mu \mathrm{m} .6=25 \mu \mathrm{m} .7=10 \mu \mathrm{m} .8=10 \mu \mathrm{m} .9=2 \mu \mathrm{m}$.

small warts $(0.5-0.7 \mu \mathrm{m})$ and deep ochre spore print (Sarnari 2005, Galli 1996, Kibby 2012). Russula aurora probably appears to be the closest (morphologically) species to this undescribed taxon but it differs from the new species by having fairly crowded pale cream lamellae with abundant forkation near the stipe, mild taste, absence of dermatocystidia in pileipellis and with low warted spores $(0.25-0.5 \mu \mathrm{m})$ aligned with few connections (Galli 1996, Kibby 2012). 


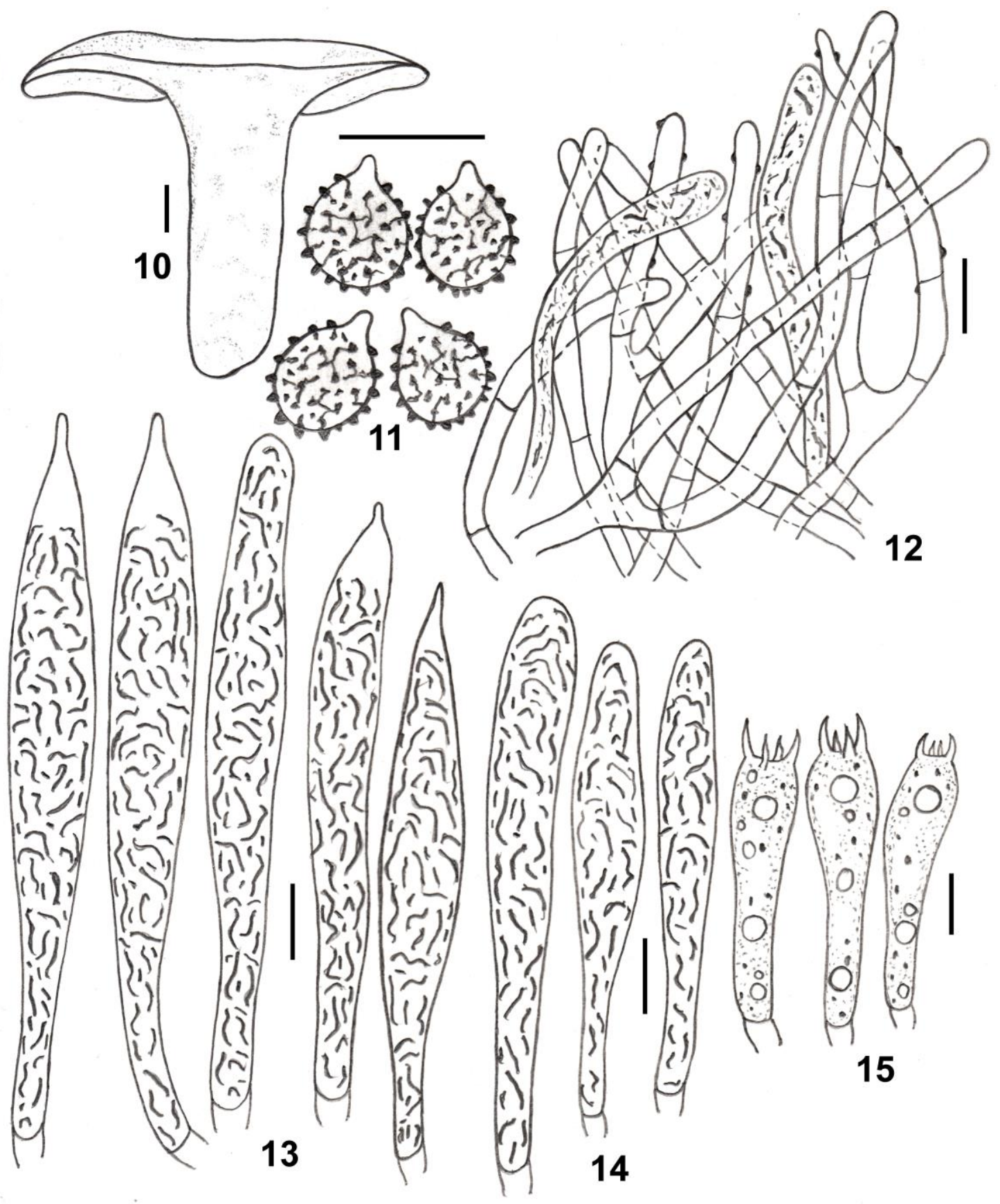

Figs. 10-15 - Russula indoarmeniaca (from holotype, AG 15-695). 10 Longitudinal section through a fresh basidioma. 11 Basidiospores. 12 Radial section through of pileipellis. 13 Pleurocystidia. 14 Cheilocystidia. 15 Basidia. Bars $=10 \mu \mathrm{m}$.

Russula aurantiaca differs from $R$. indoarmeniaca in having usually brick-orange, copper to carmine colored cap, widely spaced, rather thick, bright yellow ochre, strongly interveined lamellae, bright yellow ochre spore print and presence of mild to slightly acrid taste (Romagnesi 1967) whereas, $R$. lepidicolor has pruinose cap, lack of dermatocystidia in pileipellis, strongly encusted pilear hyphae, spore with distinctively low warts (up to $0.3 \mu \mathrm{m}$ ) almost isolated with very sparse, incomplete crests (Sarnari 2005).

Keeping in view the combination of macro- and micromorphological features along with phylogenetic evidence Russula indoarmeniaca is distinct from any previously known species of Russula. 


\section{Acknowledgements}

The authors are grateful to the Head, Department of Botany \& Microbiology \& USIC Dept. HNB Garhwal University, Srinagar Garhwal for providing all kinds of facilities during the present study and UGC for providing fellowship to AG. Miss Priyanka Uniyal, Mr. Tahir Mehmood and Mr. Upendra Singh (HNBGU) are duly acknowledged for their assistance in field. Authors thank Mr. Arun Kumar Dutta (University of Calcutta) for providing some valuable literature during this study.

\section{References}

Atri NS, Saini MK, Saini SS. 1994 - Indian Russulaceae Roze - A check list In: Current Researches in Plant Sciences Vol.1 (Sharma TA, Saini SS, Trivedi ML and Sharma M. Eds.). Bishen Singh Mahendra Pal Singh Dehradun, pp 81-93.

Bills GF. 1989 - Southern Appalachian Russulas. IV. Mycologia 81, 57-65.

Buyck B, Hofstetter V, Eberhardt U, Verbeken A, Kauff F. 2008 - Walking the thin line between Lactarius and Russula: the dilemma of Russula sect. Ochricompactae. Fungal Diversity 28, 15-40.

Buyck B, Horak E. 1999 - New pleurotoid Russula. Mycologia 91, 532-537.

Das K, Atri NS, Buyck B. 2013 - Three new species of Russula (Russulales) from India. Mycosphere 4(4), 707-717.

Das K, Dowie NJ, Li GJ, Miller SL. 2014 - Two new species of Russula (Russulales) from India. Mycosphere 5 (5), 612-622.

Das K, Sharma JR, Atri NS. 2006 - Russula in Himalaya 3: A new species of subgenus Ingratula. Mycotaxon 95, 271-275.

Das K, Van de Putte K, Buyck B. 2010 - New or interesting Russula from Sikkim Himalaya (India). Cryptogamie Mycologie 31(4), 373-387.

Das K, Sharma JR. 2005 - Russulaceae of Kumaon Himalaya. Botanical Survey of India, Govt. of India, Kolkata, India. pp 255.

Dutta AK, Paloi S, Pradhan P, Acharya K. 2015 - A new species of Russula (Russulaceae) from India based on morphological and molecular (ITS sequence) data. Turkish Journal of Botany 39, 850-856.

Galli R. 1996 - Le Russule. Edinatura. Milano.

Holmgren PK, Holmgren NH, Barnett LC. 1990 - Index Herbariorum Part I: Herbaria of the world, 86 th ed. Bronx: New York Botanical Garden, USA. pp 693.

Hongsanan S, Hyde KD, Bahkali AH, Camporesi E, Chomnunti P, Ekanayaka H, Gomes AAM, Hofstetter V, Jones EBG, Pinho DB, Pereira OL, Tian Q, Wanasinghe DN, Xu J-C, Buyck B. 2015 - Fungal Biodiversity Profiles 11-20. Cryptogamie Mycologie 36(3), 355-380.

Hyde KD, Hongsanan S, Jeewon R, Bhat DJ, McKenzie EHC, Jones EBG, Phookamsak R, Ariyawansa HA, Boonmee S, Zhao Q, Abdel-Aziz FA, Abdel-Wahab MA, Banmai S, Chomnunti P, Cui BK, Daranagama DA, Das K, Dayarathne MC, de Silva NI, Dissanayake AJ, Doilom M, Ekanayaka AH, Gibertoni TB, Góes-Neto A, Huang SK, Jayasiri SC, Jayawardena RS, Konta S, Lee HB, Li WJ, Lin CG, Liu JK, Lu YZ, Luo ZL, Manawasinghe IS, Manimohan P, Mapook A, Niskanen T, Norphanphoun C, Papizadeh M, Perera RH, Phukhamsakda C, Richter C, Santiago ALCM de A, Drechsler-Santos ER, Senanayake IC, Tanaka K, Tennakoon TMDS, Thambugala KM, Tian Q, Tibpromma S, Thongbai B, Vizzini A, Wanasinghe DN, Wijayawardene NN, Wu HX, Yang J, Zeng XY, Zhang H, Zhang JF, Bulgakov TS, Camporesi E, Bahkali AH, Amoozegar AM, Araujo Neta LS, Ammirati JF, Baghela A, Bhatt RP, Bojantchev S, Buyck B, da Silva GA, de Lima CLF, de Oliveira RJV, de Souza CAF, Dai YC, Dima B, Duong TT, Ercole E, Mafalda Freire F, Ghosh A, Hashimoto A, Kamolhan S, Kang JC, Karunarathna SC, Kirk PM, Kytovuori I, Lantieri A, Liimatainen K, Liu ZY, Liu XZ, Lücking R, Medardi G, Mortimer PE, Nguyen TTT, Promputtha I, Raj KNA, Reck MA, Lumyong S, Shahzadeh-Fazeli SA, 
Stadler M, Soudi MR, Su HY, Takahashi T, Tangthirasunun N, Uniyal P, Wang Y, We TC, $\mathrm{Xu}$ JC, Zhang ZK, Zhao YC, Zhou JZ, Zhu L. 2016 - Fungal diversity notes 367490: taxonomic and phylogenetic contributions to fungal taxa. Fungal Divers 80 (1), 1-270.

Katoh K, Misawa K, Kuma K, Miyata T. 2002 - MAFFT: a novel method for rapid multiple sequence alignment based on fast Fourier transform. Nucleic Acids Research 30, 3059 3066.

Kibby G. 2012 - The Genus Russula in Great Britain: with Synoptic Keys to Species. Published by The Author. pp 139.

Kornerup A, Wanscher JH. 1978 - Methuen Handbook of Colour. 3rd ed. London, UK.

Li GJ, Zhao D, Li SF, Wen HA. 2015 - Russula chiui and R. pseudopectinatoides, two new species from southwestern China supported by morphological and molecular evidence. Mycol Progress 14:33.

Manimohan P, Latha KPD. 2011 - Observations on two rarely collected species of Russula. Mycotaxon 116, 125-131.

Manjula B. 1983 - A revised list of the Agaricoid and Boletoid basidiomycetes from Nepal and India. Proc. Indian Acad sci. Plant Sci. 92, 81-214.

Miller SL, Aime MC, Henkel TW. 2012 - Russulaceae of Pakaraima Mountain of Guyana 2. New species of Russula and Lactifluus. Mycotaxon 121, 233-253.

Paloi S, Dutta AK, Acharya K. 2015 - A new species of Russula (Russulales) from Eastern Himalaya, India. Phytotaxa 234 (3), 255-262.

Paloi S, Dutta AK, Pradhan P, Roy A, Acharya K. 2016 - Russula buyckii, a new species of Russula subgenus Incrustatula from Eastern Himalaya, India. Phytotaxa 252 (2), 123-130.

Pradeep CK, Vrinda KB. 2010 - Ectomycorrhizal fungal diversity in three different forest types and their association with endemic, indigenous and exotic species in the Western Ghat forests of Thiruvananthapuram district, Kerala. J. Mycopathol. Res. 48(2), 279-289.

Rawla GS. 2001 - Himalayan Species of Russula Pers. Ex S.F. Gray, 1-48. In: Plant Diversity of the Himalaya (eds. PC Pande, SS Samant). Gyanodaya Prakashan, Nainital, India, pp 1-48.

Romagnesi H. 1967 - Les Russules d'Europe et d' Afrique du nord.Bordas, Paris. pp 998.

Sarnari M. 1998 - Monografia Illustrata Del Genere Russula in Europa. Tomo Primo, Italy, pp 799.

Sarnari M. 2005 - Monografia Illustrata Del Genere Russula in Europa, Tomo Secondo, Italy, 2: pp 762.

Singer R. 1986 - The Agaricales in modern taxonomy. 4rd Ed. Koeltz Scientific Books, Konigstein, pp 981.

Tamura K, Stecher G, Peterson D, Filipski A, Kumar S. 2013 - MEGA6: Molecular Evolutionary Genetics Analysis version 6.0. Molecular Biology and Evolution 30, 2725-2729.

White TJ, Bruns TD, Taylor JW. 1990 - Amplification and direct sequencing of fungal ribosomal RNA genes for phylogenetics. In: PCR protocols: a guide to methods of Amplifications (eds. M Innis, D Gelfand, J Sninsky, T. White). Academic Press New York, New York, USA. 